\title{
Dissonant role perception and paradoxical adjustments: an exploratory study on Medical Residents' collaboration with Senior Doctors and Head Nurses
}

\author{
Maddalena Fiordelli • Peter J. Schulz • Maria Caiata Zufferey
}

Received: 5 February 2013/Accepted: 21 June 2013/Published online: 1 October 2013

(C) Springer Science+Business Media Dordrecht 2013

\begin{abstract}
A good collaboration between health professionals is considered to have benefits for patients, healthcare staff, and organizations. Nevertheless, effective interprofessional collaboration is difficult to achieve. This is particularly true for collaboration between Medical Residents (MRs) and the immediate colleagues they interact with, as Senior Doctors (SDs) and Head Nurses (HNs). Role understanding is one of the factors that may explain difficulties in interprofessional collaboration. Based on this hypothesis, this paper focuses on MRs' role, devoting particular attention to differences in role perception between MRs, SDs, and HNs, and to their consequences for interprofessional collaboration. An exploratory qualitative study inspired by Grounded Theory was conducted in April 2009 in a small peripheral and non-university hospital in Switzerland. Data came from two focus groups with MRs (13), one with SDs (8), and one with HNs (7), and were analyzed using the constant comparative method. Findings show that the expected and the enacted role of MR are perceived differently by SDs, HNs and MRs themselves. To face the inconsistencies within MR's role, the three professional groups develop some adjustments that eventually prove to be paradoxical: on one side, they make collaboration possible and preserve the functioning of the ward, while on the other side they lead to mutual misunderstanding and discontent. These findings suggest that there is an urgent need of defining the role of MRs, of delimiting its
\end{abstract}

\footnotetext{
M. Fiordelli ( $($ )

Institute of Communication and Health, Università della Svizzera italiana, Via Giuseppe Buffi 13, 6904 Lugano, Switzerland

e-mail: maddalena.fiordelli@usi.ch

M. Fiordelli · P. J. Schulz

Institute of Communication and Health, Università della Svizzera Italiana, Via Buffi 13, 6904 Lugano, Switzerland

e-mail: peter.schulz@usi.ch

M. Caiata Zufferey

Département de Sociologie, Université de Genève, Boulevard du Pont d'Arve 40,

1211 Geneva, Switzerland

e-mail: M.CaiataZufferey@unige.ch
} 
boundaries and thereby distinguishing it from other health workers, and eventually of promoting a shared representation of it.

Keywords Focus group · Interprofessional collaboration · Medical Residents ·

Nurses $\cdot$ Physicians $\cdot$ Qualitative $\cdot$ Role $\cdot$ Switzerland

\section{Introduction}

A good collaboration between a variety of health professionals is considered to have benefits for patients, healthcare staff, and organizations (Vyt 2008). For patients, good interprofessional collaboration is crucial to ensure quality clinical outcomes (Hojat et al. 2001; Sterchi 2007; Thomson 2007). For healthcare staff, it improves job satisfaction (Vyt 2008). For organizations, it results in best service delivery (Johnson 2009).

Nevertheless, effective interprofessional collaboration is difficult to achieve (Thomson 2007; Ashworth 2000; Coombs and Ersser 2004; Hawryluck et al. 2002). Particularly, collaboration between Medical Residents (MRs) and the close colleagues they interact with every day, as Senior Doctors (SDs) and Head Nurses (HNs), is far from being granted. Conflicts occur often between different generations of physicians working in the hospital environment (Elkind 2009; Lancaster and Stillman 2003; Jovic et al. 2006). As for the nurse-resident interaction, few studies indicate that there is a great deal of role ambiguity between them (Hojat et al. 2001), they have significant differences in attitudes towards collaboration (Hawryluck et al. 2002), and both experience fears of poor performance and inadequacy (Grumbach and Bodenheimer 2004; McGrail et al. 2009).

A considerable literature deals with the factors that may contribute to an effective interprofessional collaboration. The most important aspects to be taken into account are communication (Suter et al. 2009; Conn et al. 2009), management approaches and tools provided for interprofessional work (e.g., time, resources, and support for collaboration) (Suter et al. 2009), personal characteristics of the individuals (Vyt 2008; Suter et al. 2009), professional culture (Hall 2005), and role understanding by colleagues and by individuals themselves who hold the role (Vyt 2008; Suter et al. 2009). Concerning this last point, some studies indicate that understanding each other's role may be difficult (Suter et al. 2009; Pellat 2005), while others underline the risk of role blurring as a potential source of conflict (Hall 2005).

The issue of role understanding provides an interesting hypothesis to elucidate the collaboration between MRs and their immediate colleagues. This issue is emphasized by the fact that the role of MRs is today particularly complex and ambiguous, and thus exposed to misapprehension. This phenomenon can be explained by means of three reasons.

First of all, the position of the MR is structurally equivocal. MRs are already part of the healthcare staff, they have significant responsibility thus they are a crucial resource for the good functioning of the organization. Yet, they are still in an educational process and their theoretical knowledge and experience are often weak. MRs have then to function "as if" they were full-fledged members of the team, even though they are still in the process of learning.

Second, the job that MRs have to do has being strongly redefined. The medical profession has been internationally challenged by the many changes of the last years in society, politics, medicine, and healthcare delivery service (Medical Professionalism Project 2002; Elston 2009; Borgstrom et al. 2010; Frenk et al. 2010; Hafferty 2006). Some scientists (Elston 2009) report a shift from "old professionalism" to "new professionalism", which can be ascribed to a loss of medical autonomy and to profound changes in the 
doctor-patient relationship. The advent of the information age and the professionalization of the patient (Elston 2009), the progress of technology (Medical Professionalism Project 2002), the increase of administrative tasks, the pressure of health insurance companies and governments towards medical practitioners (Buddeberg-Fischer et al. 2006) as well as the challenges of working in specialized healthcare teams, increasingly challenge the role of the physician (Levenson and Shepard 2008). This situation is particularly demanding for young doctors in postgraduate medical education. MRs have to construct their professional identity within this complex context with nothing to rely on but their medical education. Of course, medical schools have made several efforts to cover new pedagogical content as communication, teamwork and inter-professional learning. However, the current challenges of the medical profession have not yet been fully integrated in the teaching programs (Martimianakis et al. 2009; Erde 2008).

Third, medical residency has recently undergone important changes in the United States and in the European Union due to the introduction of work-hour restrictions (Leach 2004; Akerstedt and Kecklund 2005). In Switzerland-where residency on average lasts 5-8 years, is known for its high job demands and entails significant responsibility for patient care (Buddeberg-Fischer et al. 2008) - a law was enacted in 2005 fixing the maximum amount of working hours/week to 50 (Dami 2006). Like in other countries, this regulation was claimed to lower residents' overly long working hours (up to $80 \mathrm{~h} /$ week) (Buddeberg-Fischer et al. 2008; Prins et al. 2007). Working hour limitations have raised controversy especially among other health professionals working in the hospital, as SDs in charge of MRs' education and care organization. Main critiques are the costs for the implementation of the law, the increase of MRs' turnover, their discontinuity in patients' health care, the quality of MRs' medical training, and the erosion of medical professionalism (Elkind 2009; Peets and Najib 2012; Guyot and Monnier 2006; Monnier and Guyot 2007; Siegrist et al. 2006a; Siegrist and Giger 2004).

To summarize, being a MR today means holding a quite complex and uncomfortable position, as the position occupied within the hospital is equivocal, the challenges to face are progressively changing, and the consensus about work conditions and priorities is questioned. Because of its complexity and ambiguity, the MR's role is exposed to misapprehension.

These considerations suggest that a closer examination of $M R s^{\prime}$ role perception and of its consequences for inter-professional collaboration would be useful to illuminate residents' situation in the current context and to understand their relationships with their immediate colleagues. This is indeed an important topic, but still insufficiently understood (Chakraborti et al. 2008).

This paper aims to contribute to this investigation. Drawing on an explorative qualitative study recently conducted in Switzerland, it focuses on medical residents' role, devoting particular attention to differences in role perception between MRs, SDs, and HNs, and to their consequences for inter-professional collaboration.

The notion of role has been conceptualized in many ways. According to McKenna (2006) a role could be defined as a set of expected patterns of behavior attributable to a person occupying a particular position (the status) in a given social system. For this study it is useful to distinguish two aspects of the role: the expected role, i.e. the set of behaviors that are expected to be performed by someone in a given social position, and the enacted role, i.e. the actual set of performed behaviors (McKenna 2006). Some inconsistencies between expected and enacted role are common. In such case, adjustments are required to make collaboration possible and to preserve the system where roles are performed. It is also interesting to notice that according to social interactionists (Blumer 1969) the role is 
not fixed or prescribed, but is constantly negotiated between individuals: people develop expectations for their role and enact it on the basis of their definition of the situation in which they are. Meanwhile, other individuals concurrently develop role expectations for the interactant, and perceive his/her behaviors based on their own understanding of the situation.

Based on this brief exploration of the concept of role, this paper will (1) investigate the perceptions of MRs' expected and enacted role by the MRs themselves, by the SDs and by the HNs, and (2) clarify how these perceptions impact their inter-professional collaboration in terms of adjustments made to ensure collaboration and to preserve the functioning of the ward.

\section{Method}

An exploratory qualitative study inspired by Grounded Theory was performed in April 2009 in a small peripheral and non-university hospital in Switzerland. Grounded theory aims at developing a theoretical understanding of social phenomenon. Key features are its iterative study design and its system of analysis based on the constant comparative method (Strauss and Corbin 1990). This approach seemed particularly suitable for engaging in the development of an inductive theoretical model of role perception and of its impact on interprofessional collaboration. Focus groups (FGs) were used to engage MRs, SDs and HNs in discussions about the role of MRs and to openly explore their perceptions and understanding of it.

\section{Recruitment}

This study was supported by the direction of the hospital, who was interested in understanding the dynamics behind the work of MRs. The Human Resources department sent a letter to invite all those suitable to participate to the study in an informational meeting. All MRs', SDs and HNs of the hospital $(\mathrm{n}=35)$ were contacted. The fact that the invitation came from the hospital administration influenced the study both positively and negatively. On the one hand, we could secure high participation of a population that is usually difficult to bring together in FGs; while on the other hand, we run the risk that participants felt somewhat obliged to take part and were afraid of researchers reporting to the direction. To address this problem, during the informational meeting we provided detailed explanations on the nature and procedures of the study. We clarified that the participation was voluntary, and we ensured confidentiality and anonymity. We also pointed out that the goal of the study was to understand the dynamics of collaboration with the specific aim of improving them, and that we would present the results to all the participants in a final meeting. The good reputation of the researchers' parent organization (an independent well-known university) helped legitimating their role.

The ethical commission stated that a formal approval was not needed, since the participants weren't vulnerable and were professionals.

\section{Sample}

Twenty-eight participants gave their informed consent and constituted the final sample. Seven people declined the invitation because they were working or busy while the FGs took place. Groups were composed according to the segmentation strategy proposed by 
Morgan and Krueger (1998): They were homogeneous in terms of professional status to facilitate the discussion and to enhance the comparability of the professional categories; they were heterogeneous in terms of gender, department and duration of experience inside the hospital to maximize the variability of participants' accounts. Because of the features of the research field (a small hospital), the sample was set at the outset, and not selected progressively based on the emerging theory, as suggested by the Grounded Theory approach (cf. theoretical sampling).

Four FG were conducted: the first with $7 \mathrm{HNs}$, the second with $8 \mathrm{MRs}$, the third with 8 SDs, and the fourth with 5 MRs. HNs participating to the study were six females and one male, aged between 36 and 58 years, and with a minimum of 4 years to a maximum of 32 years of experience in the same hospital. The eight SDs were all male, from 36 to 60 years of age and with a minimum of 4 years to a maximum of 21 years of experience in that hospital. Thirteen MRs were recruited for the study, 5 males and 8 females, with a minimum age of 27 to a maximum of 33 years. Their experience in the hospital varied from 1 month to 15 years.

\section{Data collection}

A semi-structured guideline was used for focus group discussion. To develop it we referred to our research questions and transformed them into interview questions. Maxwell (2005) states that the transformation of research questions (what you want to understand) into interview questions (what you ask people in order to gain that understanding) requires creativity and insight, rather than a mechanical conversion, and depends fundamentally on how the interview questions will actually work in practice. As recommended by Patton (2002), we designed interview questions to be open ended, neutral, sensitive, and clear. We also paid attention to progress from general to specific and to avoid threatening or polemical questions. We submitted a provisional version of the guideline to a prominent physician in order to have a feedback on it. At the end, a general interview grid was developed, with some questions specific to each professional group. The key topics were: (1) Expectations of MRs' behaviors (expected role); (2) Actual MRs' actions (enacted role); (3) Judgment of the situation (inconsistencies between expected and enacted roles); (4) Respondents' own behaviors in the current situation (adjustments); (5) Changes respondents desired (if any).

The FGs lasted, on average, 120 min. They were conducted by two of the authors (moderator/co-facilitator) and audio-recorded.

\section{Analysis}

The FGs were transcribed to improve data management and content examination. Data analysis followed the constant comparative method (Strauss and Corbin 1990), which is typical of Grounded Theory.

The analysis began immediately after the first focus group and continued throughout the whole research process. After each focus group, the moderator and the co-facilitator discussed and recorded the major themes and impressions that emerged during the session. Once transcribed, then, every interview was read many times in order to become more and more familiar with its content. The prominent themes of each focus group were highlighted and contrasted with those of other focus groups. Based on this continuous process of reading and thinking about the different focus groups, memos were written to suggest 
labels and connections, to clarify and extend ideas, and to record crucial quotations (memoing).

Every interview was also systematically coded through an inductive approach: units of text (words, phrases, sentences or paragraphs) were classified into different themes or concepts (open coding); codes were then compared with respect to conformities and discrepancies, relationships between them were defined and larger categories were identified (axial coding). When new categories appeared during the analysis of an interview, the interviews which had already been examined were considered again to find the link with the retrieved categories. Thus, the interviews were coded several times. At the end, a visual model of interrelated concepts was developed (selective coding).These operations were realized with the support of the software for qualitative analysis ATLAS.ti.

One of the authors (MF) was responsible of the process of the analysis. She was in charge of collecting memos, highlighting key-quotations, proposing labels and interpretations. Another author (MCZ) systematically read the documents of analysis and questioned them. The analysis was then regularly discussed with the third author (PS). Discrepancies in the interpretation of the data were resolved by discussion among the researchers until full agreement was reached. This required researchers to work in close contact throughout the entire research process, in order to develop, as suggested by Mays and Pope (1995), a reasonable representation of the studied phenomenon.

As a final step and as announced, results were presented to all participants during a $2 \mathrm{~h}$ session to obtain respondents validation. Following the discussion and in accordance with the hospital administration, the participants freely constituted working groups in order to think over improvements of collaboration and implement changes.

\section{Results}

HNs', SDs' and MRs' perception of MRs' role

All the participants agreed on the challenging working context and on the complex position of MRs. First, participants confirmed the literature (Medical Professionalism Project 2002; Elston 2009; Buddeberg-Fischer et al. 2006; Levenson and Shepard 2008) and stated that the working context is today particularly challenging for physicians. Thus, as MRs are on the front line of patients' health care, they must have strong clinical, technological, administrative, communicative, collaborative, and adaptive competences. Second, they also agreed that the status of MRs is quite puzzling, as they are supposed to take responsibilities, but they are not yet "real doctors".

Despite this initial agreement on MRs' complex status, HNs, SDs and MRs themselves differed in describing MRs' expected and enacted role. Each professional category tended to put the accent on a particular aspect of MRs' role, thus developing different expectations and interpretations of MRs' behaviors.

\section{The MR according to HNs: the overburdened apprentice}

According to HNs, education and training are crucial in the current healthcare context, where complex skills are required. Residency should focus on learning, and MRs' main characteristic should be humility towards more experienced colleagues, included HNs. Ultimately, HNs see the MR as an apprentice. 
"The period as MR is an educational period. A MR is a person that is there to learn his/her job after having pursued a formal education." (HN, female, 49)

Yet, HNs noticed that MRs often do not take the role of apprentice. Sometimes MRs do not show enough humility because they consider themselves more educated than the nurses, and this is considered problematic:

"What is important is a lot of humility in collaboration, I think it is important. Because there are some [MRs] who are less humble only because of some theoretical knowledge they have, and this is not nice" (HN, female, 53)

This attitude is enhanced by the fact that generally MRs are given too much responsibility to ensure the good functioning of the hospital. The following quotation is explicit on this point.

"The MR on call takes over the responsibility for the whole hospital. But if you consider all the pathologies, all the patients, if you take into account that surgeons operate in the morning, you understand that in the night you can have many problematic situations. And in a moment where all the staff go home!" (HN, female, 53)

Most of all, HNs stressed the fact that MRs are not appropriately trained and supported to assume all these responsibilities. A strong consensus existed on this point: basic education is considered insufficient to enable MRs to act as "real physicians", both because of lack of theoretical knowledge and of practical experience. Moreover, HNs think that there is a gap in the introductory phase in the hospital:

“(..) the new MR is not supported by an introduction, by a training given from somebody behind his/her back that says 'you see, you are doing XX [type of exam], this is YY [type of illness], this is not correct for that, you should call somebody that....." (HN, female, 53)

HNs also consider that SDs are not involved enough with MRs:

"MRs lack role models. They lack someone who progressively... someone who takes them by the hand, and then after a while just keeps one of their fingers, and then leaves the finger, but continues to look at them from far away, and then tells them: 'Now go!'” (HN, female, 42)

In short, HNs think that MRs have high responsibilities but low support to perform their role of apprentice. Because of this, the HNs think that the MR actually acts as an overburdened apprentice, thus running the risk of medical errors. This point was stressed by all the HNs and is significantly illustrated by the following sentence of a participant:

“(...) the risk of errors is too high, his/her [MR] responsibility goes beyond his/her competences (...). My worry is that one day or another we will all be in the daily newspaper..." (HN, female, 45)

\section{The MR according to SDs: the immature professional}

SDs stated that they consider MRs as peers, that is, as members of the same professional category. In this perspective, MRs are expected to act as professionals, as responsible clinicians who are able to take medical decisions, of course under appropriate supervision. According to SDs, this requires MRs' confidence in their own skills and knowledge, awareness of their limits, and most of all passion towards their work: 
"[Referring to passion] it should be there, at least. Maybe I am too old fogey but without it you cannot... You can work, but you don't have a profession. You bring home money, but you don't live for your job. Being a MR is a way to live to reach something and then keep living doing that something." (SD, male, 53)

Yet, SDs stated that MRs seem to find it hard to act as responsible clinicians. They appear as professionally immature: they seem focused on their private lives and unwilling to sacrifice for higher aims. They also seem uncertain of their knowledge and skills, and afraid of taking responsibilities. In short, they show to lack self-confidence and passion toward their work. A SD exemplified MRs' fear of taking responsibilities with an enlightening example:

“(...) well, this is a special situation, but once the MR called me and told me: 'I have in front of me the daughter of mister $\mathrm{X}$, she wants to speak with a physician. Can you come?' He didn't think even for a moment that HE was the physician!” (SD, male, 35)

Another SD questioned about the curiosity and the passion of MRs in relation to their private life in the quote below:

"With our MRs, curiosity stops at 7 p.m. Curiosity is limited by time. At 7 p.m. curiosity is put into brackets until tomorrow at $8 \mathrm{a} . \mathrm{m}$. And this is the problem." (SD, male, 60)

This lack of flexibility was confirmed by another SD, one of the youngest:

"I ask: there is an appendectomy, do you want to do it? When he/she replies "at what time?" ok.. I go finding somebody else and I interrupt the discourse. If somebody ask me at what time you know already what this means, no? So...at what time.. the question was very wrong...he/she gave the wrong answer." (SD, male, 41)

Sometimes SDs showed some understanding toward MRs. For example, the just quoted young SD recognized at some point that MRs are today submerged by administrative tasks. In his opinion, this may explain MRs' lack of enthusiasm. As for older SDs, some of them recognized that they may be partially responsible of the relational distance with MRs: they do not have much time, they are retained from getting involved with MRs by their high turnover, they have the feeling that values and working styles are too different and thus they are themselves not so motivated to create a personal relationship with MRs. In summary, some SDs recognized that external reasons may influence the motivation of MRs. Despite this occasional understanding, however, all SDs were very critical toward MRs: ultimately, MRs are considered unreliable as physicians, they are seen as immature professionals and thus running the risk of creating a lack of medical leadership in the ward.

\section{The MR according to the MR: the "impossible" equilibrist}

MRs showed to be well aware of their contradictory status within the hospital. They know that being a MR means being a learner and a responsible clinician at the same time. In Italian the word "medical resident" is composed by the words "physician" and "assistant" (medico assistente). Referring to the concept of "medico assistente", a participant explained that:

"(...) the MR has a small contradiction in itself: there is the physician and the assistant. The doctor is by definition someone who coordinates, takes decisions, and 
even gives orders etc. Being an assistant... is anyway a strange role because (...) he is the "lightning conductor" of the whole hospital, isn't he? Except for the one who works in the kitchen or in the cleaning service [laughing]." (MR, male, 37)

Far from questioning it, MRs accept the dual nature of their status as a difficult but necessary condition to become a competent doctor. They deem the main role of the MR is to deal with this situation, meaning to act as an equilibrist to negotiate the contradictory expectations. They even stated, not without irony, that the most important attributes to succeed as MR are diplomacy and planning skills. Diplomacy is necessary with patients, relatives and of course colleagues, who very often are older and more experienced than them:

"You arrive as a MR, you are young (...). There is people here [the nurses] who have been working for 30 years, they could be your parents. You have to be very patient in the relationships, to show that you are the doctor and it's your job to take decisions. But at the same time you don't have to be too extreme and do things on your own. You need a balance. A lot of balance. (...). You'd better not argue with them. (...) You'd better have words in one ear and out from the other, otherwise you go crazy. This is stressing.. stressing. You have to be tactful, patient." (MR, female, 37)

As for planning skills, they are necessary to manage the multiple tasks MRs have to assume as learners and professionals:

"Your own organization is important. You need to be a kind of manager of yourself in order to anticipate examinations, discharges,... If you are not well organized, you don't survive.(...)" (MR, male, 37)

Yet, MRs argued that it is quite impossible to adequately combine the educational and the professional dimensions of their role. As learners, MRs occupy the most junior rank in hospital teams. This makes them becoming "everybody's lackey", thus losing credibility in front of other staff and of the patients:

"To come back to the contrast, to the contradiction between 'doctor' and 'assistant': Somebody who does every kind of duty in front of the other staff and in front of everybody else is not recognized as a person of a certain depth, isn't he? Thus it is difficult to be credible for the patients. (...) If 10000 people are continuously calling you, if the nurse comes to you and tells you 'fill this form', if the secretary and so on... well, if people around you identify you with a secretary, at the end nobody gives you credit." (MR, male, 37)

If assuming the role of "real doctor" seems to be difficult for MRs, nonetheless they are continuously required to do it, as hospital demands in terms of competence and responsibilities are high. Above all, MRs considered that the main obstacle to enacting their equilibrist role is the quantitative and qualitative work overload: "quantitative" because they have too much to do, "qualitative" because some duties are not congruent with their competences and status. Working overload thus makes it difficult to manage the learner and the professional role, and questions their planning efforts. This situation is all the more difficult that it is hardly acknowledged by other health care professionals, and this despite the enactment of the law in 2005 on work-hour limitations (Dami 2006), as the following quotation from a MR illustrates.

“SDs tell us 'good bye' at 5.30 p.m. But then, if we stay here until 9 p.m. or midnight, they do not know it, there isn't any device to count our hours, we cannot 
demonstrate it, and they minimize it. Perhaps if they were aware that we spend here our entire life, maybe then they would understand that there is a real problem of working overload." (MR, male, 37)

Because of this unacknowledged working overload, MRs consider that they act as "impossible" equilibrists, and thus they continuously run the risk of burnout.

HNs', SDs' and MRs' adjustments to ensure inter-professional collaboration

As it has been shown, HNs, SDs and MRs have different expectations concerning MRs, and all of them observe some inconsistencies between what MRs are supposed to do and what they actually do. To face this gap, the participants explained that they tend to develop some adjustments, that are specific to each professional group. By developing these strategies, participants try to make collaboration possible and to preserve the good functioning of the ward.

\section{HNs' adjustments to ensure collaboration}

According to HNs, MRs are often at risk of medical errors. To address this situation, HNs stated that they try to help the MRs. For example, they give suggestions, they check MRs' orders or they slightly correct MRs' decisions. The following quotation from a HN gives an illustration of these helping behaviors.

"Nowadays there are routine examinations, and if the MRs don't do them, the boss will blame them. So we anticipate and we take blood for these tests even if the MR does not say to do it. Then we throw away a lot of these test-tubes because some of them are unnecessary at the end. Of course this costs some money..." (HN, female, 49)

This quotation shows that HNs' helping behaviors may have some adverse consequences, in this case the waste of time and blood tests.

The HNs provided other illustrations for these paradoxical helping behaviors. For example, HNs tend to take decision in place of the MRs when these are difficult to reach. This is often the case when MRs are in the operating theatre. When something happens in the ward, HNs tend to take the responsibility to decide on their own. Nonetheless, also in this case HNs are aware of some adverse effects:

"What happens? That my MR comes back from the operating theatre exhausted, that maybe he didn't even eat, and I have to tell him: 'Listen, there is this patient who was sick, we did this this and that, but now everything is fine'. This situation could be for him an educational opportunity, but actually he didn't see it. And the most absurd is that then he has to write a letter where he motivates what was done and that he even didn't see (...)" (HN, female,50)

The previous examples show that from the point of view of the HNs, helping behaviors are necessary to protect the MRs or to ensure patients' safety. However, some negative effects can arise: waste of time and money, risk of double decisions, etc. Beyond these different inconveniences explicitly mentioned by the HNs, it is reasonable to believe that the main risk of HNs' helping behaviors is not practical but, relational: HNs' efforts may be perceived by MRs as an inappropriate intrusion in their area of expertise. This hypothesis is supported by the following quotations of two MRs: 
"Often they [HNs] are an obstacle for a beginner because they put you sticks in the spokes." (MR, female, 27)

“They expect you know, they test you, it's like you are under evaluation. They put you on trap and make crossed questions ... No, it's true, this is not a lie (...) The personnel don't forgive you." (MR, female, 28)

Even if in more instances HNs have more experience and expertise in caring for patients that MRs, demonstrating their "superiority" could be problematic because it is inconsistent with the hospital formal hierarchy.

\section{SDs' adjustments to ensure collaboration}

To make up for MRs deficiencies in taking responsibilities, SDs stated that they tend to redefine the MR as simple executor:

“(...) even in the ward I have to admit that if before the main interlocutor, for the patient, for the relatives, for the family doctor, for everybody, was ultimately the MR and everybody addressed the upper level only in special occasions, now (...) s/he $[\mathrm{MR}]$ is more and more a simple executor (...).(...) The reference points for everybody are not MRs anymore." (SD, male, 41)

As MRs are increasingly considered simple executors because unable or unwilling to take more responsibilities, SDs tend to attribute them many small tasks which seem irrelevant to their education, but to substitute them in crucial moments, that is, in decisionmaking and during significant interactions with patients and relatives:

"They take less charge. I mean, there is really a de-responsabilization. That is why there is actually more need of SDs, because in practice we are those who cover the 24 h." (SD, male, 49)

"Our reaction has been to beef up the hospital with SDs. (...). It is crucial now to have a good resident chief, because, even if s/he is someone that maybe will not stay forever, s/he is actually the one who has the ward under control." (SD, male, 41)

These adjustments are made by SDs to make collaboration possible and preserve the functioning of the hospital. However, also in this case these strategies may produce some negative effects, as the infantilization of MRs and their discredit in front of patients and healthcare staff. MRs have the impression to be used for many small things of little significance, which are not appropriate to their role. As a consequence, it becomes difficult for them to be credible in front of colleagues and patients. The following quotation of a MR clearly illustrates this:

"Because somebody who do all these duties, in the eyes of the personnel, in the eyes of everybody, is not a relevant person, no? Unless he/she has his/her own personal relevance that is evident in front of others. So it becomes difficult to value your decision and to become credible in front of the patient" (MR, female, 29)

\section{MRs' adjustments to ensure collaboration}

Overwhelmed by their tasks and lacking acknowledgement from their colleagues, MRs continuously fight against the risk of burnout. To this end, they develop their own strategies: they plan their time schedule scrupulously and strictly, they prioritize their activities, 
and they fight against others' demands in order to keep their schedule. This is how a MR explained it during a FG.

"You find yourself in stressful situations, you have to do things quickly, there are days in which you see 5, 6, 7, 10,15 patients, patients who are waiting for you, and you can't do everything at the same time, so you have to give priorities." (MR, female, 30)

The way MRs plan their work and defend their schedules is so rigorous that it can be qualified as over-organization. MRs seem to be well aware of their coping strategy, and some of them showed to be proud of being among the most organized, and to be able to experience the deriving benefits for private life. In a complex working situation at least some part of private life could still be protected if you are skilled enough, as it is explained in the following quotation of a MR.

"Last year, when I was in Department X, I was the best in organizing administrative tasks and in doing the rest of my job. I was like a machine. I think I was the only one who was able to finish before 6 p.m. I was permanently under stress, I was running the whole day, but at 6 I closed everything and went home." (MR, male, 37)

Also in this case, however, these adjustment strategies may generate some adverse effects. Over-organization makes MRs inflexible in their reaction to unexpected events. In this respect the word "machine" used by the participant in the last quotation is particularly meaningful. As a consequence, MRs are aware that they run the risk of a kind of bureaucratization of their role. The consequence of this bureaucratization is that they may lose learning opportunities, as this quote underscore:

"even when you reached the point where you are able to be very fast in dealing with all your duties because you are experienced... eh even then you finish at 6 p.m. up to your neck in it, but then you need to leave everything and to go home even if there could be something that is interesting for you to learn. It's a matter of surviving." (MR, male, 37)

MRs think that bureaucratization is their only option to survive, while waiting for the day they won't be MRs anymore. If MRs themselves are critical toward the solution they implement, SDs are even more critical. They interpret all this organization as a lack of passion and real interest toward the profession, which are fundamental to become a good doctor.

\section{Discussion}

The aim of this study was the investigation of the expected and the enacted role of MR, as this is perceived by SDs, HNs and MRs themselves, and the exploration of the adjustments made by SDs, HNs and MRs to face the inconsistencies within the role. This question was justified by the strong complexity and ambiguity of MRs' role, due to their structurally equivocal position in the hospital, to the current re-definition of the medical profession in nowadays socio-cultural context, and to the recent organizational changes in residency's work conditions.

Table 1 summarizes the results described so far and shows the different categories of perceptions and adjustments as Weberian ideal types, that is, as conceptual abstractions from reality described in their extreme pure form (Weber 1968). 
Table 1 Summary of the results

\begin{tabular}{|c|c|c|c|}
\hline & HNs & SDs & MRs \\
\hline MR's expected role & Apprentice & Professional & Equilibrist \\
\hline MR's enacted role & Overburdened Apprentice & Immature Professional & $\begin{array}{l}\text { "Impossible" } \\
\text { Equilibrist }\end{array}$ \\
\hline $\begin{array}{l}\text { Inconsistencies due } \\
\text { to }\end{array}$ & $\begin{array}{l}\text { MRs' high responsibilities } \\
\text { but low support }\end{array}$ & $\begin{array}{l}\text { Lack of MRs' self-confidence } \\
\text { and work-passion }\end{array}$ & $\begin{array}{l}\text { Unacknowledged } \\
\text { working overload }\end{array}$ \\
\hline Risk generated & Medical errors & $\begin{array}{l}\text { Lack of medical leadership in } \\
\text { the ward }\end{array}$ & MRs' burnout \\
\hline Adjustments & $\begin{array}{l}\text { Adoption of helping } \\
\text { behaviors towards MRs }\end{array}$ & Substitution for MRs & $\begin{array}{l}\text { Over-organization } \\
\text { of MRs }\end{array}$ \\
\hline $\begin{array}{l}\text { Converse effect of } \\
\text { adjustments }\end{array}$ & Intrusion in MRs' sphere & Infantilization of MRs & $\begin{array}{l}\text { Bureaucratization } \\
\text { of MRs }\end{array}$ \\
\hline
\end{tabular}

The first interesting finding of the study is the difference of MRs' role perception within the three professional groups. Existing studies have underlined that health professionals may have different conceptions of values, norms and assumptions. For example, Barrow et al. (2011) have shown that junior doctors and novices nurses hold different conceptions of power, authority and leadership. Other researchers have stressed the existence of subcultures among healthcare professionals, and their association with distinct attitudes and behavior patterns (Morgan and Ogbonna 2008). In this paper, we could see that HNs, SDs and MRs develop their own idea of MRs' expected and enacted role: HNs focus on the educational needs of MRs; SDs put the accent on the necessity for MRs to take their responsibilities as physicians; finally, MRs are well aware of their complex condition, and they think they have to deal with this phase of their career, trying to find the right balance like an equilibrist.

Differences in role perception may be explained by the inherently ambiguity of the status of MR. This includes at the same time the learner and the responsible clinician. This uncertainty gives people room for interpretation and categorization (Blumer 1969). As for the way the different professional groups interpret the MR's role, it is suitable to consider three hypothesis. A first one may be the position that the three groups occupy within the hospital and their different educational backgrounds. The expected role attributed to MRs by HNs, for example, may be understood as a way for HNs to reposition themselves in a changing context, and to gain power. On the other hand, it is possible that SDs tend to defend the integrity of the medical category by clearly attributing to MRs the status of physician and by distinguishing it from other health professionals within the hospital. This can be counted among the strategies professional elites adopt to face threats to their status from the attempts to substitute their labor (Freidson 1970; Currie et al. 2012). Another hypothesis may be that old SDs interpret the role of MR based on the way they were themselves socialized to it when they were young physicians. Indeed, in the FG they seemed to make reference to an outdated conception of physician (Elston 2009), thus confirming the generational gap between senior and young doctors found in the literature (Borgstrom et al. 2010), and more specifically the dissimilarities in terms of learning and working style (Elkind 2009; Lancaster and Stillman 2003; Jovic et al. 2006). In light of these considerations, age could be seen as an important factor for understanding role perception. This is also confirmed by the fact that younger SDs seem to be more understanding towards MRs with respect to older SDs, especially concerning MRs' work conditions. As for the last hypothesis, gender is another factor that may influence the 
understanding of the role of MR. Almost all HNs are women and all SDs are men. According to gender stereotypes, women would be more keen to understand the difficulties of MRs and to stress their need for education, while men would expect from MRs' more action and decision.

The second relevant result refers to the extent of the inconsistencies between the expected and the enacted role of MRs. Whether the MRs is supposed to act as an apprentice, a professional or an equilibrist, it seems that none of these roles may be correctly performed. The constraints of the hospital organization and the pressure of the health system seem to make it difficult to perform as a MR, independently of what a MR is supposed to be. Additionally, it seems that working-hour limitations have not completely solved MRs' overwork, as it is confirmed by other Swiss studies (Siegrist et al. 2006b).

The third finding is that, starting from their perspective on MRs' role, the various actors develop their own adjustments to interact with them and to preserve the functioning of the ward. Unfortunately, these adjustments are paradoxical since they may provoke some converse effects, thus contributing to create mutual misunderstanding: HNs want to help MRs, and by doing so they run the risk of appearing intrusive; SDs tend to balance MRs' deficiencies, and run the risk of infantilizing them; MRs try to over-organize their work, and run the risk of appearing as bureaucrats. Additionally, each strategy may reinforce the negative interpretations of the colleagues, thus creating a kind of vicious circle: MRs' strategy of over-organization may reinforce the idea held by SDs that MRs lack work-passion; SDs' strategy of substitution for MRs may reinforce the idea held by HNs that MRs lack educational support; HNs' attempts to help MRs may emphasize MRs' feelings of not being acknowledged.

\section{Limitations}

The results of any study are shaped by the methodology chosen for exploration. FGs were suitable to get insights into opinions, attitudes and behaviors of a group (Morgan and Krueger 1998). However, this method may have encouraged conformism within a same professional category, thus making discrepant experiences less likely to surface. Moreover, the setting of our study was a small peripheral, non-university hospital in Switzerland. As only four FGs could be organized we couldn't reach saturation. Even if the researchers observed an overall tendency to saturation during the analysis phase, some further data, gathered for example through observation, would have provided more details. Additionally, the specificity of the study setting raises the question of participants' autonomy and, most of all, of findings transferability.

These limitations may be partly countered. First of all we could compensate the limits of saturation with findings being confirmed by respondent validation. In the $2 \mathrm{~h}$ session of the results' presentation, the participants listened to the analysis we conducted. They were interested in discovering the perspective of their colleagues, and relieved to realize that there wasn't any guilty party: the behaviors were not the result of any ill will, but the reasonable answer to specific situations. Concerning participants' autonomy, this was initially questioned by the role of the hospital direction as stakeholder. Yet, the informational meeting made before the study could clarify the nature and procedures of the research process, so that a procedural agreement with the participants was reached. As for findings transferability to other hospitals, this remains the main limitation of the study. It can be partially nuanced by the fact that the majority of respondents (17) had been previously working in other Swiss and international hospitals, and their comments referred to their current and past experiences. Despite this, the study would be strengthened by having multiple sites. 
Research and practical implications

This was an exploratory study. To confirm the results and expand on them, it would be important to use another data collection technique (e.g., observation) and to address this topic on a larger scale. Extend the study to multiple sites would allow to test the transferability of the findings.

As for practical implications, our findings suggest that there is an urgent need of defining the role of MRs, of delimiting its boundaries and thereby distinguishing it from other health workers, and eventually of promoting a shared representation of it. To this end, it would be important to prioritize what MRs need to achieve during their clinical practice, in an effort similar to that recently provided in the US (Graham et al. 2009a, b). Meanwhile, redistributing some tasks inside the hospital (in particular administrative tasks) and creating intermediate figures between MRs and SDs (e.g., Senior MRs or tutors) could help in reducing MRs' overwork and in reducing the distance between senior and junior physicians. It would also be crucial to strengthen and structure learning opportunities. Several options can be suggested concerning this point: it could be useful to increase the number of physicians who can serve as good role-models, and to give them the possibility (in terms of time and training) to take on this task; a progressive introduction of MRs in the different departments could also support their learning process; it would be useful to think over the possibility for HNs to assume some formal teaching role towards MRs, legitimating in this way their experience and their expertise. Finally health workers should be trained to positive communication styles in order to promote collegiality and teamwork, and should have settings where effective communication can occur.

These inputs were developed by the participants and the hospital administration in four interdisciplinary working groups that took place after the end of the study. The discovery of others' perspectives made the participants understand the behaviors of their colleagues and motivated them in finding shared solutions. As a consequence, a pilot project was recently implemented in the Department of General Medicine of the hospital to improve the organization of MRs' work and their collaboration with the other health professionals.

\section{Conclusion}

This study deals with dissonant role perception as explanation for problematic interprofessional collaboration. The literature often reports poor relationships between the various professional groups, emphasizing anger, conflict, and differences in attitudes towards collaboration (Thomson 2007; Ashworth 2000; Coombs and Ersser 2004; Hawryluck et al. 2002). Our results provide an illustration of these difficulties, highlighting in addition the logics behind the perspective of each actor and the consequences for collaboration. Despite these findings are situated in the Swiss context, this understanding can be applied to other contexts and situations, thus increasing the conceptual generalizability of the results (Green and Thorogood 2004).

\section{References}

Akerstedt, T., \& Kecklund, G. (2005). The future of work hours-the European view. Industrial Health, 43, 80-84.

Ashworth, P. (2000). Nurse-doctor relationships: Conflict, competition or collaboration. Intensive \& Critical Care Nursing, 16(3), 127-128. 
Barrow, M., McKimm, J., \& Gasquoine, S. (2011). The policy and the practice: Early-career doctors and nurses as leaders and followers in the delivery of health care. Advances in Health Sciences Education: Theory and Practice, 16, 17-29.

Blumer, H. (1969). Symbolic interactionism: Perspective and method. Englewood Cliffs, NJ: Prentice-Hall.

Borgstrom, E., Cohn, S., \& Barclay, S. (2010). Medical professionalism: Conflicting values for tomorrow's doctors. Journal of General Internal Medicine, 25(12), 1330-1336.

Buddeberg-Fischer, B., Dietz, C., Klaghofer, R., \& Buddeberg, C. (2006). Swiss residents' arguments for and against a career in medicine. BMC Health Services Research, 6, 98.

Buddeberg-Fischer, B., Klaghofer, R., Stamm, M., Siegrist, J., \& Buddeberg, C. (2008). Work stress and reduced health in young physicians: Prospective evidence from Swiss residents. International Archives of Occupational and Environmental Health, 82, 31-38.

Chakraborti, C., Boonyasai, R. T., Wright, S. M., \& Kern, D. E. (2008). A systematic review of teamwork training interventions in medical student and resident education. Journal of General Internal Medicine, 23(6), 846-853.

Conn, L. G., Lingard, L., Reeves, S., Miller, K.-L., Russell, A., \& Zwarenstein, M. (2009). Communication channels in general internal medicine: A description of baseline patterns for improved interprofessional collaboration. Qualitative Health Research, 19(7), 943-953.

Coombs, M., \& Ersser, S. J. (2004). Medical hegemony in decision making: a barrier to interdisciplinary working in intensive care. Journal of Advanced Nursing, 46(3), 245-252.

Currie, G., Lockett, A., Finn, R., Martin, G., \& Waring, J. (2012). Institutional work to maintain professional power: Recreating the model of medical professionalism. Organization Studies, 33(7), 937-962.

Dami, F. (2006). Médecins hospitaliers et loi fédérale sur le travail. Revue Médicale Suisse, 2, 2211-2212.

Elkind, M. S. V. (2009). Teaching the next generation of neurologists. Neurology, 72(7), 657-663.

Elston, M. A. (2009). Remaking a trustworthy medical profession in twenty-first century Britain? In J. Gabe \& M. Calnan (Eds.), The new sociology of the health service. London, New York: Routledge.

Erde, E. L. (2008). Professionalism's facets: Ambiguity, ambivalence, and nostalgia. The Journal of Medicine and Philosophy, 33(1), 6-26.

Freidson, E. (1970). Profession of medicine: A study of the sociology of dominance: The social structure of medical care. New York: Aldine.

Frenk, J., Chen, L., Bhutta, Z. A., Cohen, J., Crisp, N., \& Evans, T., et al. (2010). Health professionals for a new century: Transforming education to strengthen health systems in an interdependent world. Lancet, 376, 1923-1958.

Graham, M. J., Naqvi, Z., Encandela, J. A., Bylund, C. L., Dean, R., \& Calero-Breckheimer, A., et al. (2009a). What indicates competency in systems based practice? An analysis of perspective consistency among healthcare team members. Advances in Health Sciences Education: Theory and Practice, 14(2), 187-203.

Graham, M. J., Naqvi, Z., Encandela, J. A., Harding, K. J., \& Chatterji, M. (2009b). Systems-based practice defined: Taxonomy development and role identification for competency assessment of residents. Journal of Graduate Medical Education, 1(1), 49-60.

Green, J., \& Thorogood, N. (2004). Qualitative methods for health research. London: Sage Publications.

Grumbach, K., \& Bodenheimer, T. (2004). Can health care teams improve primary care practice? JAMA: The Journal of the American Medical Association, 291(10), 1246-1251.

Guyot, J. P., \& Monnier, P. (2006). Revue Médicale Suisse Edito: Une défaite déguisée en victoire ... et qui visera bientôt les praticiens. Revue Médicale Suisse, 2(81), 2211-2212.

Hafferty, F. W. (2006). Definitions of professionalism: A search for meaning and identity. Clinical Orthopaedics and Related Research, 449, 193-204.

Hall, P. (2005). Interprofessional teamwork: Professional cultures as barriers. Journal of Interprofessional Care, 19(Supp 1), 188-196.

Hawryluck, L. A., Espin, S. L., Garwood, K. C., Evan, C. A., \& Lingard, L. A. (2002). Pulling together and pushing apart: Tides of tension in the ICU team. Academic Medicine, 77(10 suppl), S73-S76.

Hojat, M., Manigone, S., Nasca, T., Cohen, M., Gonnella, J., \& Erdmann, J., et al. (2001). The Jefferson scale of physician empathy: Development and psychometric data. Educational and Psychological Measurement, 61(2), 349-365.

Johnson, C. (2009). Health care transitions: A review of integrated, integrative, and integration concepts. Journal of Manipulative and Physiological Therapeutics, 32(9), 703-713.

Jovic, E., Wallace, J. E., \& Lemaire, J. (2006). The generation and gender shifts in medicine: An exploratory survey. BMC Health Services Research, 6, 55.

Lancaster, L. C., \& Stillman, D. (2003). When generations collide. New York: HarperCollins.

Leach, D. C. (2004). Resident duty hours: The ACGME perspective. Neurology, 62, E1-E2. 
Levenson, R. D. S., \& Shepard, S. (2008). Understanding doctors: Harnessing professionalism. London: King's Fund.

Martimianakis, M. A., Maniate, J. M., \& Hodges, B. D. (2009). Sociological interpretations of professionalism. Medical Education, 43(9), 829-837.

Maxwell, J. A. (2005). Qualitative research design: An interactive approach. London/New Dehli: Sage, Thousand Oaks.

Mays, N., \& Pope, C. (1995). Rigour and qualitative research. British Medical Journal, 311, 109-112.

McGrail, K. A., Morse, D. S., Glessner, T., \& Gardner, K. (2009). "What is found there'”: Qualitative analysis of physician-nurse collaboration stories. Journal of General Internal Medicine, 24(2), 198-204.

McKenna, E. (2006). Business psychology and organisational behaviour. New York: Psychology Press.

Medical Professionalism Project. (2002). Medical professionalism in the new millennium: A physicians' charter. Lancet, 359, 502-522.

Monnier, P., \& Guyot, J. P. (2007). Plaidoyer pour un retour de la médecine aux médecins, ou le blues des chefs de services universitaires. Revue Médicale Suisse, 3, 2195-2197.

Morgan, D. L., \& Krueger, R. A. (1998). The focus group kit: Volumes 1-6. London, New Delhi: Thousand Oaks, Sage.

Morgan, P. I., \& Ogbonna, E. (2008). Subcultural dynamics in transformation: A multi-perspective study of healthcare professionals. Human Relations, 61, 39-65.

Patton, M. (2002). Qualitative research and evaluation methods. London, New Dehli: Thousand Oaks, Sage.

Peets, A., \& Najib, T. (2012). Restricting resident work hours: The good, the bad, and the ugly. Critical Care Medicine, 40(3), 960-966.

Pellat, G. C. (2005). Perceptions of interprofessional roles within the spinal cord injury rehabilitation team. Journal of Therapy and Rehabilitation, 12(4), 143-150.

Prins, J. T., Gazendam-Donofrio, S. M., Tubben, B. J., van der Heijden, F. M. M. A., van de Wiel, H. B. M., \& Hoekstra-Weebers, J. E. H. M. (2007). Burnout in medical residents: A review. Medical Education, 41(8), 788-800.

Siegrist, M., \& Giger, M. (2004). Assistenten-und Assistentinnenumfrage 2003 aus Sicht der Leiterinnen und Leiter von Weiterbildungsstätten. Schweiz Ärztezeitung, 85(42), 2262-2266.

Siegrist, M., Orlow, P., \& Giger, M. (2006a). Effets de la loi sur le travail sur la formation postgraduée des médecins et temps consacré à cette dernière: enquête auprès des responsables d'établissements de formation. Bulletin des médecins suisses, 87(26), 1204-1207.

Siegrist, M., Orlow, P. \& Giger, M. (2006b). Formation postgraduée et situation professionnelle vues par les médecins-assistants. Bulletin des médecins suisses, 87, 379-386.

Sterchi, S. (2007). Perceptions that affect physician-nurse collaboration in the perioperative setting. Association of Operating Room Nurses Journal, 86(1), 45-57.

Strauss, A. L. \& Corbin, J. (1990). Basics of qualitative research. London: Sage publications.

Suter, E., Arndt, J., Arthur, N., Parboosingh, J., Taylor, E., \& Deutschlander, S. (2009). Role understanding and effective communication as core competencies for collaborative practice. Journal of Interprofessional Care, 23(1), 41-51.

Thomson, S. (2007). Nurse-physician collaboration: A comparison of the attitudes of nurses and physicians in the medical surgical patient care setting. Medical-Surgical Nursing, 16(2), 87-91.

Vyt, A. (2008). Interprofessional and transdisciplinary teamwork in healthcare. Diabetes/Metabolism Research and Reviews, 24(Supp 1), S106-S109.

Weber, M. (1968). Economy and society: An outline of interpretive sociology. New York: Bedminster Press. 